\title{
Cardiovascular effects of active short-term holidays
}

\author{
Gunther Neumayr ${ }^{1 *}$, and Peter Lechleitner ${ }^{2}$ \\ ${ }^{1}$ From the Medical Office of Dr. Neumayr, Lienz, Austria \\ ${ }^{2}$ Medical Center Symbiomed, Lienz and Department of Internal Medicine, Hospital Lienz, Austria
}

A vacation is considered essential to achieve recovery from the stress of work. To what extent the duration of a vacation and the activities therein have an impact on health and wellbeing remains unclear because we lack scientific measurements of physiological parameters before, during, and after a vacation [1].

Current holiday behavior reveals a tendency towards several shortterm vacations not exceeding one week. Whether a break of just one week has perceivable health effects has not been investigated so far. Activity programs such as playing golf, Nordic walking, or riding a bicycle with electric motor support (e-biking) are popular, are known for their low to moderate exercise intensity and therefore feasible for nearly everybody, including persons with poor cardiorespiratory fitness. Such vacation activities might accelerate the recovery process and enhance the potential health effects of a short-term vacation. The degree of regeneration can be measured by cardiovascular parameters such as blood pressure, heart rate, performance capacitiy, and cardiac diastolic function [2].

The East Tyrolean Health Tourism Study is the first to investigate the cardiovascular effects of a short-term vacation with different activities on healthy vacationers. The results were published recently [3] and are summarized here: Fifty-two healthy vacationers spending one week in East Tyrol participated in two types of vacation activities (golf vs. Nordic walking or e-biking [nw\&eb]). In the former group 30 subjects played golf for 33.5 hours per week, and in the nw\&eb group 22 engaged in Nordic walking or e-biking for 14.2 hours per week. Cardiovascular parameters such as performance capacity, blood pressure, heart rate profiles and cardiac diastolic function were measured by a cardiopulmonary exercise test, holter ECG and echocardiography performed one day before and after the stay. There was a significant decrease in body weight of $1.0 \mathrm{~kg}$ in the nw\&eb-group but not in the golf group. In both groups we noted a reduction of blood pressure and heart rate, which was marked and significant only in the golf group. We observed no significant changes in performance capacity, but did note an improvement of cardiac diastolic function in both groups. All results are given in the Table 1.

Vacation is a form of macrorecovery and is likely to be a more powerful recovery opportunity than regular free evenings or weekends because of two underlying mechanisms. The first passive mechanism is a direct release from job demands, the second is an active one expressed by spending time on valued non-work activities of one's own choice, such as hobbies, family, or sports. In sports, active recovery with low intensities at a work rate $<30 \%$ of $\mathrm{VO}_{2}$ max accelerates the regeneration process by faster lactate degradation in comparison to passive recovery in sedentary subjects [4]. Therefore, we assumed that a vacation with an activity program might provide earlier and more complete recovery than that achieved by a simple holiday. Playing golf, Nordic walking and e-biking are activities of low to moderate exercise intensity, feasible even for untrained persons.
Table 1. Cardiovascular parameters in the golf group and the Nordic walking plus e-biking group (nw\&eb group) one day before and after vacation. (Within the group: vs prevacation $*=\mathrm{p}<0.01$; vs pre-vacation $* *=\mathrm{p}<0.005$; vs. prevacation $* * *=\mathrm{p}<0.001$; Results are expressed as median with interquartile range). $\mathrm{NW} \& \mathrm{E}=$ Nordic Walking and E-Bike, HR $=$ heart rate, $\mathrm{SBP}=$ systolic blood pressure, $\mathrm{DBP}=$ diastolic blood pressure, $\mathrm{W}=\mathrm{Watt} ; \mathrm{VO}_{2}$ $\max =$ maximal oxygen consumption, LV-Tei $=$ left ventricular Tei index, NT-proBNP $\stackrel{2}{=}$ NT-pro brain natiuretic peptide

\begin{tabular}{|l|l|l|l|l|}
\hline & Golf-Group & NW\&E-Group & \\
\hline & pre-vacation & post-vacation & pre-vacation & post-vacation \\
\hline $\mathrm{HR}_{\text {mean }}$ & $81(73 ; 93)$ & $77(75 ; 84) * *$ & $81(76 ; 87)$ & $76(70 ; 86)$ \\
\hline $\mathrm{HR}_{100 \mathrm{w}}$ & $123(108 ; 136)$ & $112(104 ; 137) *$ & $116(105 ; 132)$ & $112(98 ; 133)$ \\
\hline $\mathrm{HR}_{\text {max }}$ & $156(142 ; 165)$ & $155(142 ; 165)$ & $155(143 ; 164)$ & $155(137 ; 169)$ \\
\hline $\mathrm{SBP}_{\text {rest }}$ & $130(117 ; 135)$ & $119(111 ; 128)^{*}$ & $125(114 ; 136)$ & $122(111 ; 142)$ \\
\hline $\mathrm{DBP}_{\text {rest }}$ & $80(73 ; 84)$ & $75(69 ; 77) *$ & $84(78 ; 87)$ & $81(74 ; 84)$ \\
\hline $\mathrm{SBP}_{100 \mathrm{~W}}$ & $162(148 ; 184)$ & $153(131 ; 180) *$ & $143(136 ; 182)$ & $150(130 ; 170)$ \\
\hline $\mathrm{W}_{\text {max }}$ & $150(124 ; 199)$ & $151(128 ; 184)$ & $175(125 ; 216)$ & $172(132 ; 229) *$ \\
\hline $\mathrm{VO}_{2 \max / k g / \min }$ & $26(23 ; 35)$ & $26(21 ; 34)$ & $28(25 ; 35)$ & $28(21 ; 35)$ \\
\hline $\mathrm{LV}-\mathrm{Tei}^{\prime}$ & $0.61(0.50 ; 0.69)$ & $0.51(0.44 ; 0.64)$ & $0.51(0.44 ; 0.64)$ & $0.45(0.35 ; 0.56) * * *$ \\
\hline $\mathrm{E} / \mathrm{e}^{\prime}$ ratio & $8.0(6.4 ; 9.5)$ & $7.8(6.4 ; 8.5)$ & $7.8(6.9 ; 10.1)$ & $7.4(6.7 ; 8.3) *$ \\
\hline $\mathrm{NT}-$ proBNP & $74(32 ; 101)$ & $62(43 ; 88)$ & $44(31 ; 80)$ & $46(26 ; 99)$ \\
\hline
\end{tabular}

The cardiovascular benefits observed consisted in a marked reduction in systolic and diastolic blood pressure, in the lowering of heart rates and an improvement of cardiac diastolic function. The reduction of blood pressure was much more pronounced in the golf group because of extensive isometric handgrip training in golf. The mean reduction in blood pressure in the golf group was 11.0/5.0 $\mathrm{mmHg}$, which is similar to the results of a recent meta-analysis by Cornelissen in which isometric handgrip training was shown to reduce blood pressure very effectively by $13.5 / 6.1 \mathrm{mmHg}$ [5]. Due to the results of our study playing golf seems to be the even more effective antihypertensive treatment than walking or biking. The active vacation lowered the heart rate in both groups. The median reduction was 3 beats/min in the golf group and 5 beats/min in nw\&eb group, with unchanged characteristics in circadian profiles and unchanged numbers of ventricular and supraventricular premature beats. The reduction in heart rate was very similar to the findings in our AMAS 2000 trial in patietnts with metabolic syndrome [6].

\section{Conclusion}

In conclusion, the data of the East Tyrolean Health Tourism Study prove that just a one-week vacation with various activity programs is able to induce several improvements in cardiovascular parameters and confidently may be recommended as an excellent recovery program for cardiovascular regeneration.

Correspondence to: Gunther Neumayr, MD, Michaelsgasse 20, A-9900 Lienz, Austria, E-mail: neumayr.g@aon.at

Received: March 18, 2018; Accepted: April 02, 2018; Published: April 06, 2018 


\section{References}

1. De Bloom J, Kompier M, Geurts S, De Weerth C, Taris T, et al. (2009) Do we recover from vacation? Meta-analysis of vacation effects on health and well-being. J Occup Health 51: 13-25. [Crossref]

2. Olshansky B, Sabbah HN, Hauptman PJ, Colucci WS (2008) Parasympathetic nervous system and heart failure: pathophysiology and potential implications for therapy. Circulation 118: 863-871. [Crossref]

3. Neumayr G, Lechleitner P (2018) Effects of a one-week vacation with various activity programs on cardiovascular parameters. J Sports Med Phys Fitness doi: 10.23736/ S0022-4707.18.08221-X. [Epub ahead of print].
4. Spierer DK, Goldsmith R, Baran DA, Hryniewicz K, Katz SD (2004) Effects of active vs. passive recovery on work performed during serial supramaximal exercise tests. Int J Sports Med 25: 109-114. [Crossref]

5. Cornelissen VA, Fagard RH, Coeckelberghs E, Luc Vanhees L (2011) Impact of resistance training on blood pressure and other cardiovascular risk factors. A metaanalysis of randomized, controlled trials. Hypertension 58: 950-958. [Crossref]

6. Neumayr G, Fries D, Mittermayer M, Humpeler E, Klingler A, Schobersberger W, et a (2014) Effects of hiking at moderate and low altitude on cardiovascular parameters in male patients with metabolic syndrome: Austrian Moderate Altitude Study (AMAS). Wilderness Environ Med 25: 329-334. [Crossref]

Copyright: (C2018 Neumayr G. This is an open-access article distributed under the terms of the Creative Commons Attribution License, which permits unrestricted use, distribution, and reproduction in any medium, provided the original author and source are credited. 